Revista Iberoamericana. Vol. LXIV, Núms. 184-185, Julio-Diciembre 1998; 573-586

\title{
OBRERAS DEL PENSAMIENTO Y EDUCADORAS DE LA NACIÓN: EL SUJETO FEMENINO EN LA ENSAYÍSTICA FEMENINA DECIMONÓNICA DE TRANSICIÓN
}

\author{
POR \\ MARISElle MelÉNDEZ \\ Purdue University
}

\begin{abstract}
La madre y la esposa serán durante los siglos las que lleven la primacía de toda evolución sociológica, porque ellas son y serán el cimiento sobre el cual se yergue el hogar.

Entrando ahora á determinar las proyecciones de la civilización en otro orden de actuación, la mujer frívola está llamada á escuchar sólo el eco de su propia voz en el derruido caserón de las añejas prácticas.

Tendrán opción á que las atiendan sus semejantes, no aquellas que se ocupan de sí mismas, sino las que canten á través de la meditación, de la filosofía, de la igualdad; aquellas que sientan para el pueblo y con el pueblo canten.
\end{abstract}

Clorinda Matto de Turner, Boreales, Miniaturas y Porcelanas [énfasis mío]

El epígrafe anterior constituye parte de la biografía que Clorinda Matto de Turner redacta de la poeta mexicana Laura Méndez de Cuenca, a quien ella considera una de esas mujeres que en "otro orden de actuación" y por su "doble gloria como mujer y como cerebro pensante" servirá de guía y educadora a las mujeres que se encuentran "perdidas" en el "vicio repudiado" (138). Matto de Turner pasa a citar un poema de la escritora mexicana, donde esta última describe la encrucijada en que se ve la mujer cuando no tiene como guía a una semejante que la sepa orientar y encaminar. Los versos a continuación ilustran no sólo la tesis de Matto con relación a la importancia del rol de la mujer como base de la nación, sino que destacan a su vez el funesto fin que se le deparaba en la sociedad a quien olvidara seguir la norma.

Laura Méndez escribe,

Á la fuga de un huésped trashumante,

Tu seno maternal horror te inspira

Y aprietas á su curva vergonzante

El áureo cinturón de la hetaíra.

Tú con despego criminal que aterra

Apartas tu regazo al pequeñuelo:

Pobres hijos que arrojas en la tierra

A la dudosa protección del cielo!

Roto el lazo social, el deber roto,

Flotas por cima del desprecio humano, 
Arrogante y altiva como el loto

Que emerge de los limos del pantano.

¿Y hablas de redimirte? ¡Qué ironía!

Tiene surcos tu faz y tienes canas:

Para aguardar la Muerte tu desecho

Abre sus fauces y su vientre ensancha;

Vendrá primero el numerado lecho,

Después la disección sobre la plancha. (Boreales 139, énfasis mío)

Los versos citados subrayan esa ambivalencia a la que la mujer del siglo XIX se vio expuesta como parte del rol que le exigía la sociedad. Por otra parte, los versos ponen de relieve la manera en que la mujer intelectual de la época visualizaba esa problemática. A la mujer disoluta ("mesalina") le deparaba la desaparición del escenario nacional. Su desaparición será una violenta: primero será tragada por el vientre de la Muerte, luego, será disecada o sea, analizada cuidadosamente. Su cuerpo yerto servirá como objeto de estudio que intentará explicar su propensión a la transgresión de las normas expuestas por el sector patriarcal. Clorinda Matto de Turner, por medio de la redacción de biografias como la de Laura Méndez de Cuenca, parece ofrecer un remedio a la situación que sufren algunas mujeres en la sociedad debido a su negación a suscribirse al rol de madre ("Tu seno maternal horror te inspira"). Tal anulación (muerte) en el plano nacional es un elemento que preocupaba a la autora. La anulación puede ser evitada si la mujer se puede guiar por los ejemplos de otras mujeres que sepan balancear su rol como "mujer" (madre y esposa) y como "cerebro pensante" (137-8). Clorinda Matto define el rol que debe ocupar la mujer dentro del nuevo "orden de actuación" (pasadas ya las luchas de independencia) y en procesos que intentaron dar forma a las naciones emergentes. Su rol debe ser uno activo e intelectual. La mujer escritora, añadirá Clorinda Matto, será la más capacitada para definir su rol. La escritora peruana, como muchas otras en el resto de Hispanoamérica, se dio a esta tarea de reformular y revisar el rol de la mujer en la historia y su sociedad actual. El género ensayístico les sirvió a todas como un espacio desde el cual articular su posición en la sociedad.

Este trabajo prestará atención al género ensayístico debido al papel fundamental que jugó durante el siglo XIX y las primeras décadas del siglo XX, en relación a los temas de la identidad cultural, la raza, la nación y la problemática de género sexual. El ensayo, por su hibridez discursiva, le ofreció a los escritores de la época un espacio flexible desde el cual articular sus proyectos nacionales. ${ }^{1}$ Dentro de un género literario al cual equivocadamente se le ha hecho sinónimo de la claridad, existió una compleja red discursiva cuya pasión creativa y estética corría a la par de la poesía y la novela. Uno de los aspectos más importantes para entender las intenciones presentes en los ensayos decimonónicos y

\footnotetext{
${ }^{1}$ El ensayo podía tomar la forma de una carta, una confesión, una conferencia, una oración o un artículo científico, periodístico o sociológico. Doris Meyer señala que en el caso de las mujeres el ensayo fue moldeado como ensayo-carta, ensayo-confesión, ensayo-novela o ensayo-diario de viajes entre otros (5). Meyer sugiere que la falta de estudios criticos sobre el ensayo radica en que su potencial "hibridez estética" desafia su definición (5).
} 
posteriores, es prestar atención a su carácter retórico, a su faceta persuasiva. Como señala Theodor W. Adorno, la función retórica del ensayo no es meramente transmitir las ideas del ensayista sino sugerir e inducir una experiencia en el pensamiento del lector (169). El ensayo instiga a pensar dialécticamente. Se destaca por su carácter crítico y creativo. Es en su elemento narrativo, en su andamiaje retórico y poético y en su autoconstitución ficcional, como apunta Roberto González-Echevarría, donde el ensayo cobra mayor lucidez (15). ${ }^{2}$

Los estudios críticos sobre los ensayistas decimonónicos han prestado poca atención a la utilización que hicieron de este género discursivo las mujeres escritoras de la época. ${ }^{3}$ Al igual que Bello, Lastarria, Martí y Bolívar, entre otros, ellas articularon sus preocupaciones sobre asuntos nacionales por medio de la producción ensayística. La utilización de un discurso que se asociaba usualmente con lo masculino es utilizado por diversas autoras para abogar por la inclusión de la voz femenina en los debates políticos sobre la nación. El propósito de mi artículo es prestar atención a la importancia que cobró la ensayística femenina en las discusiones que surgieron en las últimas décadas del siglo XIX y principios del XX, sobre el rol que la mujer debía ejercer en el plano nacional. El estudio examina específicamente algunas de las estrategias discursivas que utilizan las escritoras en su articulación de un sujeto femenino nacional y las ambigüedades inherentes que tal proyecto lleva consigo. El trabajo también explora la manera en que el tema de la educación femenina sirve como instrumento para abogar por la inclusión de la mujer en la esfera de lo público, para así convertirla en un elemento vital y visible para el progreso de la nación. El tema de la pedagogía se convierte en un arma retórica que se extiende al terreno de la familia, lo moral y lo intelectual. Las escritoras, por medio de sus discusiones sobre la educación nacional y femenina, instituyen una labor correctiva cuyo fin último consiste en educar a la sociedad en lo concerniente al rol que la mujer debe ocupar en la nación. Su enmendación se vale de una retórica que yo llamaría lidiadora y laboral, cuyo fin es ordenar la nación de manera que incluya el nuevo "orden de actuación" que ocuparía la mujer y al cual alude Clorinda Matto de Turner en el epígrafe. Con "retórica lidiadora" me refiero a la utilización por parte de las ensayistas de un lenguaje que denota combate, lucha, y que alude a actos de heroísmo, triunfos, defensa, audacia e invasión. Lo que llamo retórica laboral se asocia con la utilización de un lenguaje por parte de las escritoras que apunta a la imagen de la mujer y la maternidad como obreras de la sociedad cuyo rol se define por su labor activa e imprescindible en el futuro del progreso de la nación. En sus ensayos, la maternidad, lo

\footnotetext{
${ }^{2}$ Roberto González-Echevarría apunta que el crítico y los lectores tienden a obviar los aparatos retóricos a través de los cuales el ensayo establece "su performatividad" (15). La performatividad toma lugar cuando el ensayista elabora una relación de sus intenciones entre la búsqueda de una presencia y verdad, y la ficción creada para llevar a cabo tal tarea (16).

${ }^{3}$ Doris Meyer con su edición del volumen de ensayos críticos Reinterpreting the Spanish American Essay. Women Writers of the $19^{\text {th }}$ and $20^{\text {th }}$ Centuries (1995), llama la atención acerca de la falta de estudios críticos que se enfoquen en el género del ensayo. Meyer comenta la tendencia de los críticos a canonizar el ensayo como un género asociado con la figura masculina del intelectual, olvidando los muchos ensayos escritos por mujeres en donde las escritoras de la época utilizaron este género para apropiarse de un espacio intelectual desde el cual podían hablar de la marginalización en que se encontraban (4).
} 
conyugal y lo intelectual, se visualizan como una profesión. Mi trabajo tomará como foco de discusión algunos de los ensayos que se relacionan con los temas de la educación de la mujer y su rol en la sociedad y que fueron redactados por las siguientes autoras: Gertrudis Gómez de Avellaneda (Cuba, 1816-73), Juana Manuela Gorriti (Argentina, 1819-92), Clorinda Matto de Turner (Perú, 1854-1909) y Adela Zamudio (Bolivia, 1854-1928 ). ${ }^{4}$

En los ensayos a estudiarse de las cuatro autoras citadas se desprende un deseo inminente de cruzar las fronteras que dividen al espacio público del privado por medio del reclamo al estudio como arma de desarrollo y progreso. El reclamo se enmarca dentro del contexto nacional y cultural. El lenguaje representa el arma que facilita el cruce y la invasión de límites o fronteras que subsisten entre ambos espacios. Las fronteras, aquellos límites finitos en que descansan otras naciones y que, según Benedict Anderson, contribuyen a la noción de la nación como comunidad política imaginada como limitada y soberana (15), cuando se trasladan al plano del género sexual apuntan a espacios de diferencia que las escritoras perciben como receptáculos de transformaciones necesarias para generar cambios. Las fronteras o límites emergen como un espacio productor de "procesos híbridos" que incorporan, generan y producen nuevos diálogos (Bhabha 4). Gómez de Avellaneda, Gorriti, Clorinda Matto y Zamudio, exploran esas fronteras impuestas por los aparatos masculinos hegemónicos a las mujeres y destacan cuán variables e inestables son. Las fronteras representan, como sugiere Geoffrey Bennington, lugares de comunicación, de intercambio, de asociación y no asociación, de separación y articulación (121). En los ensayos a discutirse, las zonas de las diferencias (las fronteras) generan un disentimiento que intenta abrir (cuestionar) las bases en que esas diferencias están basadas. ${ }^{5}$ El lenguaje utilizado por las escritoras en los ensayos a continuación representa esa retórica lidiadora con la cual ellas invaden discursivamente esas fronteras. ${ }^{6}$ Los ensayos de estas mujeres pueden considerarse como parte de lo que Mary Louise Pratt ha denominado "gender essay" (115). Pratt se refiere a textos escritos durante los pasados 180 años cuyo tópico es el estatus

\footnotetext{
${ }^{4}$ Esta selección no pretende ofrecer un cuadro totalizador de la producción de las escritoras citadas en torno a sus discusiones sobre la mujer, la educación y la nación. Su producción ensayística fue cuantiosa al igual que la cantidad de asuntos que abarcaron: religión, amor, prácticas culturales, la higiene, la salud y la raza, entre otros. Debido a los límites del artículo he hecho una selección pragmática de estas cuatro autoras. La hipótesis que desarrollo se puede relacionar con muchas otras escritoras que publicaron en el siglo XIX y las primeras décadas del siglo XX. Una ojeada a la lista que ofrece Clorinda Matto de Turner en su ensayo "La obreras del pensamiento en la América del Sud" (1895) de mujeres que publicaron copiosamente en el siglo XIX, muestra la falta de estudios críticos exhaustivos acerca del rol de la educación femenina en el pensamiento nacional y las estrategias retóricas que dominaron sus escritos. La edición de ensayos críticos de Doris Meyer citada anteriormente, representa una introducción, revaloración y apertura a la producción ensayística femenina .

${ }^{5}$ Otras dimensiones de la violencia surgen como postulan Andrew Parker, Mary Russo, Doris Sommer y Patricia Yaeger, cuando las identidades de la nación se distinguen por sus diferencias, y la nación (en este caso el aparato político), ve la necesidad de "administrar" la diferencia a través de actos violentos de censura, coerción económica, tortura física y brutalidad policíaca (5).

${ }^{6}$ En el contexto de mi ensayo la nación se define como un proceso que se articula en la narrativa, la cual, como argumenta Homi Bhabha, se compone de estrategias textuales, desplazamientos metafóricos y estratagemas figurativas que se utilizan para representar a la nación (2).
} 
y la realidad de la mujer en la sociedad moderna (115). Es un tipo de literatura contestataria cuyo objetivo es interrumpir el monólogo masculino o retar su reclamo a un monopolio de la cultura y la historia (115). Estos ensayos intentan proponer formas alternas de intelectualidad (115).

Gertrudis Gómez de Avellaneda publica en 1860 el ensayo titulado "La mujer" como respuesta a la negativa por parte de los académicos españoles a aceptarla como integrante de la Real Academia Española debido a la naturaleza de su sexo. ${ }^{7}$ La reacción por parte de Gómez de Avellaneda ha sido descrita como una "belicosa confrontación" que la indujo a defender su posición como mujer y ser pensante (Santos 135). Avellaneda comienza discutiendo la importancia que le ha asignado los anales de la religión a la mujer. Luego pasa a destacar las cualidades de carácter que la han distinguido y que se derivan de su valor y patriotismo. En la tercera parte, se enfoca en la capacidad de la mujer para ejercer funciones en el gobierno y la administración de intereses públicos. Finaliza discutiendo la capacidad científica, artística y literaria que posee ésta.

En el plano religioso, Avellaneda subraya el rol imprescindible que la mujer ha ocupado por su supremacía de los afectos, su gran intuición, y su sentido de maternidad que no radica según ella únicamente "en el sentido material de la palabra, sino en la del alma" al ser escogida una mujer como madre de quien será "representante del mundo regenerado" (286). La imagen que se erige de María, la madre de Jesucristo, es la de un ser humano con gran fortaleza quien "se alza reina por derecho en los vastos dominios del sentimiento" (287). María como la mujer "que venció sola" y sin intervención de ningún hombre, funciona en contraposición a Eva, quien fue corrompida por su contacto con él (287). El lenguaje que se utiliza para destacar la figura de María apela a esa retórica lidiadora a la que me referí anteriormente. Se recalca la imagen de María como la mujer que lucha y triunfa. De ella, la mujer ha heredado también ese "heroísmo religioso" que hace contradecir toda postura por parte del hombre al referirse a ella como "débil" (287).

La alusión a la debilidad le sirve a Avellaneda para abundar y cuestionar en la segunda parte del ensayo, las contradicciones que la frase "sexo débil" encierra cuando se refiere a la mujer. Su intención es destacar la relativización que caracteriza al adjetivo "débil". Avellaneda sostiene que "la organización física" no debe utilizarse por parte de los hombres como una excusa para generalizar sobre la naturaleza de la mujer (292). Según ella, en la naturaleza del "vigor intelectual y moral" es donde radica la fuerza de la mujer (292). Su inteligencia y carácter no son sinónimos de debilidad, ya que junto con su heroísmo apuntan a la superioridad de la mujer. Este heroísmo también nace del corazón y del sentimiento, ya que según Avellaneda, "los más gloriosos hechos, consignados en los anales de la humanidad, han sido siempre obra del sentimiento; que los más fuertes héroes han sido en todo tiempo los más ricos corazones" (293). Una vez más, la autora enfatiza la fuerza y la lucha, como los elementos que mejor describen a la mujer. Basándose en el libro que según ella, es el "más antiguo y auténtico", Avellaneda ofrece una lista de mujeres que guerrearon "blandiendo espadas", "dispuestas a vencer y a morir con sus conciudadanos", defendiendo

\footnotetext{
${ }^{7}$ Para una biografia detallada sobre la vida y obra de la autora, ver Ondina Montoya de Zayas ("La Avellaneda en su tiempo" 111-31).
} 
ciudades, "combatiendo" y administrando con "recta justicia" (294). ${ }^{8}$ Es interesante notar que la fuerza de la mujer sobrepasa lo espiritual y lo intelectual y se desplaza al terreno de lo físico. A diferencia de la violencia utilizada por gobernantes masculinos para establecer su poder, la mujer ha sido capaz de utilizarla con un fin incorruptible: el de establecer justicia. Avellaneda concluye esta segunda parte del ensayo comentando de manera irónica que a pesar de que las mujeres no han sido "educadas para sufrir fatigas, afrontar peligros, defender nuestros intereses públicos y conquistar laureles cívicos" (296), ellas han sabido cómo manejarse en todas estas esferas, lo que pone en tela de juicio su supuesta debilidad.

El énfasis en la fortaleza física de la mujer le sirve a Avellaneda para exponer la idea de que la "organización física" de la mujer no es incompatible con las más "poderosas facultades del alma" (297). La mujer ha sabido, a pesar de la poca educación que le han ofrecido, crear un balance en su comportamiento dentro del espacio público y el privado. En la tercera parte de su ensayo Avellaneda enfatiza que esa fuerza física e intelectual le ha facilitado a la mujer el desarrollarse éxitosamente en el gobierno de los pueblos y administración de los intereses públicos. Lo anterior desmantela "las egoístas teorías del sexo dominador" que creían que la grandeza de la mujer venía de "inspiraciones divinas" (298). Para enfatizar aún más la fortaleza intelectual que destaca a la mujer, Avellaneda concluye en la cuarta parte del ensayo postulando que "la fuerza moral e intelectual" de la mujer se iguala a la del hombre en el campo de las literaturas y las artes, ese espacio que siempre se había destacado por la hegemonía masculina (302). Si las mujeres no se han desarrollado en algunos campos como lo es el científico, es porque "las puertas de los graves institutos" les han permanecido cerradas (302). Sin embargo, el "exclusivismo varonil" y su dominio en las "academias barbudas" no han podido evitar el desarrollo intelectual de la mujer. La fuerza intelectual y moral de la mujer es un elemento concomitante del éxito y progreso de la nación. Como concluye Avellaneda, "En las naciones en que es honrada la mujer, en que su influencia domina en la sociedad, allí seguro hallaréis civilización, progreso, vida pública" (306). El dominio de la mujer a través de las variantes de su fuerza (divina, humana, moral, fisica e intelectual), garantiza el orden en la sociedad. Como contraposición, finaliza Avellaneda, "[e]n los países en que la mujer está envilecida" se encuentra "la servidumbre, la barbarie, la ruina moral" que condena a la sociedad (306). La mujer por sus sacrificios, luchas, desarrollo y fuerza intelectual y moral, debe ganarse el respeto de aquellos que se han autodenominado como los representantes del poder.

La escritora argentina Juana Manuela Gorriti también destaca en sus ensayos la importancia de la mujer como partícipe de los nuevos proyectos nacionales. ${ }^{9}$ No tan radical como Avellaneda, Gorriti postula en muchos de sus ensayos la figura de la madre como eje

\footnotetext{
${ }^{8}$ Mary Louise Pratt destaca la inserción en los ensayos de las escritoras decimonónicas de "catálogos históricos" como una de las categorías discursivas que caracteriza al "gender essay" (17). Los catálogos consisten en la enumeración de mujeres que se destacaron en la historia. Su fin es afirmar la realidad de la mujer como agente social, desmintiendo el rol negado en la historia tradicional (17). La segunda categoría discursiva que se introduce en este tipos de ensayos, según Pratt, es el comentario analítico sobre la condición social y espiritual de la mujer como un intento de proponer formas alternas de intelectualidad (18).

${ }^{9}$ Detalles sobre la biografia de Gorriti se pueden encontrar en Francine Masiello, Between Civilization and Barbarism. Women, Nation, and Literary Culture in Modern Argentina (46-51).
} 
ordenador de la sociedad y esencial para el futuro de la nación en cuanto a su rol como educadora y mujer dispuesta al sacrificio. En "La voz del patriotismo" (1875) Gorriti apunta que las hijas, imitando a las madres, pueden convertirse en "útiles ciudadanas" lo que junto con la educación pública representaría dos aspectos esenciales para el fortalecimiento de la república (62). Su rol como madres y "consoladoras de los desamparados" constituye un elemento que puede unir a las mujeres en una "fraternidad" que en última instancia fortalecerá a la patria (62). En los ensayos, "Recuerdos del dos de mayo" (1866) y "Las dos madres" (1866), refiriéndose a las guerras civiles acontecidas en el Perú, Gorriti subraya que la mujer debe ser partícipe del dolor y la gloria de las naciones ayudando a los hombres en el campo de batalla. En el caso del último ensayo, ella alude a la historia de las dos madres que se arriesgan a trabajar en los campos de batalla curando a los enfermos e insistiendo que establecer una enfermería detrás de las baterías era la manera más efectiva para ayudar a quienes luchaban por la patria. En el sacrificio y riesgo de proteger a sus hijos radica, según Gorriti, su heroísmo: “¡Madres! lo que hace sublime vuestro amor, es la parte inmensa que en él tiene el heroísmo" (107). El esfuerzo eminente (heroísmo) que las lleva a realizar "hechos extraordinarios" en servicio de la patria es el aspecto que destaca a la madre (Diccionario de la lengua 703). La madre y su labor en el ámbito del espacio público es parte imprescindible en la unidad y desarrollo de las naciones.

En un discurso leído para el Club de la Sección de Literatura en La Plata, Gorriti elabora más detalladamente la labor que ejerce la madre como eje ordenador de la nación. Criticando el hecho de que se envíen a los hijos a estudiar a Europa desde pequeños y sin haberse "formado [...] en el amor del hogar", Gorriti destaca la importancia de la educación de la madre en el ámbito de lo doméstico para fundar una sociedad ajena al caos (130). La educación que se recibe fuera del seno materno es capaz de generar únicamente tiranías, desenfrenos, crimen, atrocidades, y por ende, la ruina (130). La educación que provee la madre será esencial para lo que según Gorriti constituye "la suerte futura de nuestras sociedades" (131).

Sin embargo, la maternidad en estos ensayos no se define exclusivamente como un estado sino como una labor al servicio de la patria. Es una especie de trabajo que provee grandes remuneraciones: orden, progreso, moralidad y justicia. La mujer constituye un factor importante para que la sociedad funcione, por lo que su rol no debe estar subordinado al hombre sino que debe ser paralelo a él. ${ }^{10}$ Ella es el complemento esencial. En el prólogo a su libro La cocina ecléctica (1877), Gorriti comenta que la mujer en su rol de "sacerdotisa y guardián natural" del hogar ha sido responsable de los "ínclitos genios" en la historia como Plutarco, Virgilio, Corneille, Racine, Châteaubriand, Hugo y Lamartine, entre otros (16). La lectura y el estudio que Gorriti ha hecho de ellos le ha facilitado entender que estos hombres ilustres lo llegaron a ser debido a que "tuvieron todos, á su lado, mujeres hacendosas y abnegadas que los mimaron, y fortificaron su mente con sus suculentos bocados, fruto de la ciencia más conveniente a la mujer" (16). La mujer, inclusive en el

${ }^{10}$ Esta posición debe entenderse como respuesta al debate nacional en torno a la mujer que acaeció en la Argentina durante el siglo XIX. Como apunta Francine Masiello, los intelectuales de la época reforzaron los deberes de la mujer como madre y esposa de manera que satisfaciera los proyectos de estado (53-4). La mujeres eran concebidas como las encargadas del futuro de la nación por lo que su rol debía contenerse dentro del plano de la domesticidad (53-54). 
espacio del hogar y en lo que se le ha querido reclamar como su rol tradicional, es capaz de generar un espacio en donde su trabajo (el cocinar, alimentar y el mimar) ha servido como instrumento esencial para el desarrollo del hombre. Siguiendo un poco el tono irónico y la línea de pensamiento de sor Juana cuando alegaba que "Si Aristóteles hubiese guisado, mucho más hubiera escrito" (453), Gorriti subraya la importancia de la mujer en la historia como sujeto activo, laborioso e influeyente en quienes se les ha otorgado el poder de gobernar la nación. Como apunta Francine Masiello, refiriéndose al caso de Argentina en el siglo XIX, la mujer (y entre ellas Gorriti), se veía como la fuerza guiadora detrás de las misiones patrióticas (57). En Gorriti, la mujer se destaca no por su función exclusivamente procreadora, sino por su labor educativa y de guardiana del futuro de la nación logrado por medio de su rol activo en la sociedad. ${ }^{11}$

El énfasis en el rol activo de la mujer en el ámbito nacional es un tema evidente en los ensayos de Clorinda Matto de Turner. ${ }^{12}$ En sus innumerables escritos, en las imprentas y revistas que fundó, y en los periódicos que dirigió, se manifiesta una preocupación constante en definir y reformular la posición de la mujer como miembro de la nación. Los ensayos a discutirse a continuación se destacan por una aproximación a la problemática de la mujer en la nación que se enfoca en la mujer como obrera de la nación y en su función de educadora. En "La mujer, su juventud y su vejez" (1884), Matto de Turner critica la educación superficial que recibe la mujer y que nada más sirven de adornos por no tener ninguna sustancia. El cantar o el bailar no son elementos que desarrollan el pensamiento de la mujer. La mujer debe recibir "una educación completa y sólida" que nutra sus deberes como hija, esposa y madre (Tradiciones 219). Matto deja claro que ese deber de madre no debe consistir en peinar, bañar o alimentar al niño, sino en educar, ya que de ésto depende "la felicidad de toda una sociedad" (Tradiciones 219). Esta educación es un deber "a Dios y a la Patria"; un deber que la mujer debe cumplir con pleno conocimiento de lo que separa al vicio de la virtud, pero la virtud como "la actividad o fuerza [...] para producir" un fin de manera eficaz (Diccionario de la lengua 1346). Es una virtud que consiste en el vigor y el poder de obrar rectamente (Diccionario de la lengua 1346).

La importancia de ser educada en los campos del conocimiento no funciona únicamente para el servicio de la patria, sino para la mujer misma, cuando una vez llegada la vejez y su atractivo físico haya desaparecido, al menos le quedará un bagaje de conocimiento que no se podrá borrar y que compartirá en reuniones públicas, sintiéndose un ser útil en la sociedad (Tradiciones 220). La mujer debe "invadir" la sociedad con su conocimiento pero éste debe estar al servicio de "las labores domésticas" (Tradiciones 219). Este tipo de mujer no debe acumular libros y vivir en aislamiento sino que debe estar consciente de su trabajo en la sociedad. Este tipo de mujeres debe separarse de "aquella clase de sabias despreocupadas que pasan la vida con la frente enardecida por el estudio é inclinadas sobre el bufete donde fojean volúmenes sin fin; olvidando que su deber las reclama con vozincesante" (Tradiciones 219). La mujer debe integrar su conocimiento a la sociedad. Debe trabajar constantemente

\footnotetext{
"Francine Masiello comenta que las mujeres en esta época adoptaron un "feminismo relacional", posición donde la mujer tomaba posturas políticas como apoyadoras de sus esposos y niños (68). El hogar por lo tanto, proveyó un espacio para la autoría femenina y un diálogo emergente acerca de las letras y la política (Masiello 68).

${ }^{12}$ Información detallada sobre la biografía de Matto de Turner se puede encontrar en Mary C. Berg.
} 
para preparar a su familia y cumplir un rol vital en la nación. Aunque Matto de Turner todavía privilegia el espacio de lo doméstico como áquel donde la mujer debe guardar su rol más activo, el hecho de que éste se defina por "una educación completa y sólida", por un separarse de las tareas superficiales, por un no dedicarse exclusivamente a cocinar, limpiary atender a los niños, hacen que la función de la mujer sea una diferente, ya que radica en la labor continua por medio del conocimiento (Tradiciones 219). Su trabajo en el ámbito de lo privado, no equivale, como señala en su ensayo "El gólgota y la mujer" (1884), a que la mujer viva bajo las cadenas de la esclavitud. Como Matto de Turner señala, el nuevo rol de la mujer en la sociedad debe erradicar esa esclavitud en que se ha mantenido a la mujer: "Fijando la vista al grandioso cuadro del pasado, que se llama historia" se ve que "la mujer está bajo la más vergonzosa sugeción y esclavitud" (Tradiciones 211). La escritora deja claro que el rol de la mujer en el plano de lo doméstico no radica en el sometimiento ya que como ella sugiere, Dios le debe decir "al varón dominador del Universo" que "La mujer es tu compañera, no tu esclava" (Tradiciones 211). La mujer debe coexistir a la par del hombre y no sujeta a él.

Matto de Turner, por medio de una retórica lidiadora y laboral, destaca la presencia fuerte que la mujer debe tener en la sociedad. Su nuevo rol, definido por medio del discurso femenino, es visualizado por la autora como una "invasión" en la historia cuyo fin es crear un cambio, adquirir visibilidad por medio de la acción y de la palabra. En el ensayo "Para ellas", Matto de Turner subraya ese rol activo y vital de la mujer que es tan imprescindible, no únicamente para la sociedad, sino para su desarrollo individual: "El espíritu atrofiado por la ignorancia, es como el organismo inerte por la acción de la parálisis" (Tradiciones 252). La mujer, sin el conocimiento para llevar a cabo su trabajo, es un ser entorpecido por la acción; un ser nulo en el plano social. Lo que va a generar su movimiento es la educación, el conocimiento: "La instrucción ha traido el término propio para la mujer, conquistándonos el respeto de todos" (Tradiciones 252). La nueva posición que la mujer debe adoptar como ser integrante de la sociedad es definida como el triunfo sobre el pasado. Los resultados de esa lucha le deben conferir a la mujer el respeto de aquellos que con su poder la han subordinado.

Finalmente, Corinda Matto en su ensayo "La obreras del pensamiento en la América del Sud" (1895), de manera más controversial y directa, subraya la ilustración que la mujer ha logrado "en las postrimerías del llamado siglo admirable" (Boreales 246). Su trabajo en la sociedad ha impulsado "el carro del progreso" de lo cual las naciones se han beneficiado (Boreales 246). La autora destaca que la mujer ha luchado sin cesar enfrentándose a obstáculos para reclamar una libertad bien merecida: "cruzó barreras de siglos, repitiendo apenas, con miedoso sigilo, las mágicas palabras: libertad, derecho" (Boreales 246). La mujer, a pesar de haber estado circunscrita a los dominios del hogar, ha sabido cómo transgredir y cruzar las fronteras que separan al espacio privado del público para ilustrar lo que el centro debe a la periferia. Los límites se visualizan como espacios que reconfiguran la retórica de la diferencia. Desde ese espacio, Clorinda Matto denuncia a "los obscurantistas, los protervos y los egoístas interesados en conservar á la mujer como instrumento del placer y la obediencia pasiva" (Boreales 247). Estos hombres deben entender que con la República "la lucha heroica" debe separar éxitosamente el pasado (el egoísmo) del presente (razón, libertad y justicia) (Boreales 248). Dentro de esta lucha heroica la mujer debe aparecer "con 
los arreos de la victoria, alta la frente, alumbrada por los resplandores de la inteligencia consciente; fuerte el brazo por el deber y la personería" (Boreales 248). La mujer es aquella que ha lidiado y triunfado por medio del conocimiento, un conocimiento que no se limita al espacio de lo doméstico vis a vis lo público. En su caso uno alimenta al otro; sin el primero el segundo se debilita.

Matto concluye que "la cruzada redentora" no debe parar (Boreales 248). La causa de la mujer constituye un proceso que todavía tiene más frutos que dar. La autora define la causa como una "batalla" entre el "Egoísmo" vestido de raídas telas y "la Razón, engalanada con los atavíos de la Libertad y alentada por la Justicia" (Boreales 247-8). Lo femenino en esta lucha (Libertad, Justicia) será lo que triunfará al final gracias al uso de la razón. Por lo tanto, como señala más adelante, "postergar la ilustración de la mujer es retardar la ilustración de la humanidad" (Boreales 248). Se recalca nuevamente esa función de la mujer que se desplaza más allá del ámbito privado y se extiende a la humanidad. Sin ella el hombre no es capaz de sobrevivir los avatares de la historia: "Degradad á la mujer, pervertir su sentido moral y pronto habréis hecho del hombre un ser envilecido, sin fuerzas para luchar contra los más sombríos despotismos, porque la mujer es el alma de la humanidad" (Boreales 249). La mujer es lo que da aliento, fuerza, lo que alimenta la mente y el espíritu, la que entiende, quiere y siente. ${ }^{13}$ Es su compañera, no su esclava. Clorinda Matto concluye que América se ha convertido en el árbol bajo cuya frondas "trabajan millares de mujeres productoras que no sólo dan hijos á la patria, sino, prosperidad y gloria!” (Boreales 250). Matto de Turner resalta aquí la figura de la escritora, la intelectual. Aquellas "verdaderas heroínas" que "luchan día a día, hora tras hora" dentro y fuera de las configuraciones del espacio doméstico "para producir el libro, el folleto, el periódico, encarnados en el ideal del progreso femenino" (Boreales 252). La periferia se escinde y da paso a la creación de otro centro: emerge la mujer escritora como aquella que por el poder de la letra encaminará y dirigirá la lucha hacia el avance de la mujer en la sociedad. ${ }^{14}$ La escritoras son, según Matto de Turner, "las obreras del pensamiento" que día a día "continúan laborando" por la emancipación del resto de las mujeres (Boreales 252). Una vez más se subraya la figura de la mujer, en este caso la escritora, como la que labora asiduamente por el progreso de la sociedad de la cual ella es parte esencial. Su labor en este caso estará al servicio del resto del conglomerado femenino que todavía vive bajo los lazos de la subyugación y la esclavitud. Ella será su guía.

El interés de las escritoras en redefinir su posición en la sociedad por medio de abogar en favor de la educación como instrumento esencial para el progreso, es una preocupación que siguió existiendo en las primeras décadas del siglo XX, cuando todavía diversos proyectos y reformas nacionales estaban en proceso. Para finalizar, me gustaría aludir a Adela Zamudio como una entre tantas escritoras de transición que discutieron el rol imprescindible de la educación para el desarrollo de la mujer. Zamudio, figura importante

\footnotetext{
${ }^{13}$ Todas estas palabras son definiciones que se derivan de la palabra "alma" y que se encuentran en el Diccionario de la lengua española. Real Academia Española (65).

${ }^{14} \mathrm{El}$ ensayo termina ofreciendo un catálogo de las diferentes escritoras hispanoamericanas que se han estado destacando en la sociedad por medio de la escritura. Ver nota número 8 para recordar la función que según Mary Louise Pratt, tenían estos catálogos históricos en las redacciones de los ensayos femeninos.
} 
en los debates de las reformas educacionales en Bolivia, escribe en 1914 su ensayo "Temas pedagógicos", en el cual denuncia la falta de instrucción secundaria para la mujer en Bolivia, quien después de finalizar su sexto año tiene que regresar a su casa. Zamudio aboga por la eliminación de la enseñanza religiosa como parte de la educación oficial y por la existencia de una "enseñanza de todos los ramos, y muy especialmente, la instrucción moral" 183). ${ }^{15}$ Valiéndose de las alusiones al rol de la madre como semilla de la instrucción moral de los ciudadanos, Zamudio pasa a reclamar una educación más completa para la mujer que la prepare para dirigir el futuro de la patria. Sin embargo, esta alusión al papel de la madre le sirve como excusa para revisar y reconfigurar el rol de la madre en cuanto a su influencia social y desarrollo individual. La madre como la percibe Zamudio es una obrera.

Zamudio coloca a la mujer dentro y fuera del espacio doméstico para articular su posición sobre la función y necesidad de la educación de la mujer. ${ }^{16} \mathrm{Si}$ la sociedad espera que la mujer se guíe por la moralidad y evite las pasiones, debe entender que la instrucción y no la ignorancia es el vehículo que puede ayudar a la mujer a actuar rectamente. Según Zamudio, "el ejemplo de los padres" y "algunas máximas evangélicas no son suficientes para instruir a la mujer" (184). Representan aspectos muy generales. Si a "la futura madre de la familia" añade Zamudio, se le pide actuar, hay que presentarle claramente las doctrinas por las cuales debe guiarse para que así "sean capaces de determinar sus acciones" (185). Además, habría que discutir claramente qué se le pide a la mujer cuando se le habla de virtud. ¿Dónde radica la línea divisoria entre el bien y el mal? Sólo cuando entiendan esta compleja diferenciación, las mujeres podrán juzgar con "lógica, rectitud y con independencia" (186). Podrán también entender las contradicciones que destacan a muchas de las ideologías (religiosas) que se les tratan de inculcar. Carecer de criterio, apunta Zamudio, constituye "un ente peligroso en la sociedad" (186). La mujer debe entonces desarrollarse como individuo primero. Sólo a partir de este punto podrá cumplir la función que de ella se espera en la sociedad. La mujer no debe considerarse exclusivamente como madre sino también como un individuo capaz de formar criterios y tomar decisiones rectas y provechosas.

La crítica de Zamudio también va dirigida a la insuficiencia de la doctrina religiosa para educar a la mujer. En la actualidad, añade la autora, las jóvenes viven "contagiadas" por "el espíritu ligero y superficial" (187). Como resultado, hay que buscar alternativas que salven a las jóvenes (sector que a ella le preocupa) de vivir preocupadas por lo trivial en vez de prepararse por lo que puedan contribuir al desarrollo de la sociedad. La indiferencia con la que vive la mujer en la niñez y la "manía de la oración" con la que vive en la edad madura, representan extremos de los cuales hay que alejarse (187). Zamudio sostiene que "la devoción no se debe visualizar como sinónimo de virtud ya que se puede ser devota sin ser virtuosa" (188). La solución, según la autora, radica en dejarle claro a la mujer por medio de la enseñanza, que "su influencia social" en "asuntos trascendentales" radica en entender su rol como "obrera" dentro del contexto de la familia y la sociedad (189).

\footnotetext{
${ }^{15}$ Detalles sobre la vida de Adela Zamudio y su rol en el desarrollo de los debates nacionales en Bolivia en torno a la educación se pueden encontrar en Leonardo García Pabón.

${ }^{16}$ Mary Louise Pratt se refiere a esta tendencia por parte de las escritoras de la época como una "ideología ecléctica" en la cual sus discusiones sobre el estatus de la mujer operaban dentro y en contra de las ideologías patriarcales del género sexual (17).
} 
La imagen de la mujer como obrera constituye un elemento importante con el cual Zamudio concluye su ensayo. La autora critica que la sociedad sólo tiene en cuenta a la mujer "como esposa y como madre" y ve con reservas a la mujer que por su trabajo es capaz de ser "fuerte e independiente" (191). Zamudio intenta conciliar la idea de la mujer como madre y obrera. La mujer debe ocupar un rol activo en la sociedad trabajando para el bien de la nación. La tarea puede ser lograda una vez que la mujer tenga acceso a una educación adecuada y completa. La mujer debe constituir un ser útil y diligente dentro del dearrollo de la sociedad. El mantenerse ocupada con el trabajo la liberará de los pensamientos superficiales en que se ocupan muchas mujeres jóvenes. El trabajo, según Zamudio, "le procurará doble beneficio: la libra del servilismo y la preserva de los devaneos de una imaginación ociosa" (191). Zamudio no parece visualizar una contradicción entre la mujer como madre y la mujer como individuo, siempre y cuando ambas trabajen en función del desarrollo de la sociedad. Al igual que las escritoras discutidas anteriormente, Zamudio aboga por la visibilidad de la mujer dentro del plano nacional.

La nación se convierte en el hogar de todas las mujeres y todas, como concluye Zamudio, "madre, esposa, hija, hermana, tía, amiga, todas estamos llamadas a un destino supremo: la maternidad moral" (192). La moral, lo que "no cae bajo la jurisdicción de los sentimientos, por ser de la apreciación del entendimiento o de la conciencia" (Diccionario de la lengua 894), es el numen de ese nuevo tipo de maternidad de la que habla Zamudio. Para lograr un entendimiento y laborar en función de lo mejor para la sociedad en general, es preciso recibir una educación que prepare íntegramente a la mujer en la sociedad ya que "para todas hay hogar, y que para todas hay en el hogar, santos deberes, y dichas inefables" (192). Utilizando imágenes relacionadas con el espacio de lo doméstico, Zamudio aboga por un tipo de hogar diferente para la mujer. Un hogar que fluctúa dentro y fuera de los contornos del ámbito doméstico y que trasciende a lo nacional. La inclusión de las mujeres en la sociedad no debe estar basada únicamente en el rol de la madre como reproductora, sino como obrera de la felicidad de ese gran hogar que es la nación. Madres, esposas, hijas, amigas, a pesar de sus diferencias, ocuparán posiciones importantes dentro del imaginario nacional.

En suma, los ensayos citados demuestran la manera en que las escritoras intentaron definir el rol de la mujer a partir de lo que muchos pueden concebir como ideas contradictorias, las cuales fluctuaban entre la imagen de éstas como esposas y madres, y por otro lado, como ciudadanas e integrantes de la nación. Tal contradicción no parecía existir para las escritoras, sino que era parte de sus negociaciones entre el centro y la periferia, el pasado y el presente. Según el contexto de estos ensayos, la mujer no produce exclusivamente por medio de la sexualidad, sino también por medio de las ideas alcanzadas por el conocimiento. Las alusiones a la madre siempre estarán ligadas a la acción, al trabajo que las mujeres deben ejercer dentro y fuera del ámbito doméstico. La reconfiguración de la mujer en el plano nacional va ligada a un abogar por el acceso al estudio. La defensa de la educación de la mujer es caracterizada por una lucha o actitud lidiadora contra la ideología dominante de la época. Sobresale la figura de la mujer que invade por medio del conocimiento intelectual pero que entiende que éste no necesariamente se debe concebir únicamente en función del plano maternal sino que debe extenderse a un plano más universal: la humanidad. 
Debido a la inestabilidad y amenaza que acompañaba tal visibilidad de la mujer, y que la autoras reclamaron en sus debates y discusiones, sus posturas no pudieron desligarse del asunto de lo doméstico (el hogar, la madre, la esposa). La retórica de lo doméstico funcionó para reformular la posición de la mujer no únicamente como guía de sus hijos sino como ser activo y pensante en la sociedad, como compañera y no como subalterna, como sujeto y no como objeto. Bell Hooks apunta que el proceso de convertirse en sujeto emerge cuando la persona entiende cómo las estructuras de dominación actúan y funcionan sobre sus vidas (15). También cuando el ser humano desarrolla un pensamiento y una conciencia crítica que le facilita proponer nuevos hábitos de ser y resistir desde el espacio marginal de la diferencia internamente definido (Hooks 15). Si pensamos en los ensayos discutidos de Gómez de Avellaneda, Gorriti, Matto de Turner y Zamudio, se puede visualizar cómo ellas por medio del discurso y desde su posición de marginadas, cuestionaron los parámetros establecidos por la sociedad masculina dominante entendiendo cómo sus estructuras de dominación operaban sobre ellas. La revisión de su posición (históricamente definida por el hombre) y el reclamo de cambiar ese rumbo, constituyen parte integral de su conciencia crítica. La escritura se convierte en esta disyuntiva en arma de combate. Las palabras tan citadas por los intelectuales masculinos durante la época de posindependencia (lucha, heroísmo, sacrificio, invasión, patria, nación, virtud) adquieren un sentido diferente cuando cruzan las fronteras entre lo público y lo privado. La mujer emerge como sujeto a través de una retórica lidiadora que apela a la importancia de la mujer como obrera del pensamiento y como ser activo y vital para garantizar el progreso de la nación. El acceso a la educación y el conocimiento constituía su arma para liberarse de lo que Laura Méndez de la Cuenca llamó "la disección sobre la plancha".

\section{Obras CITADAS}

Adorno, Theodor. "The Essay as Form". New German Critique 32 (1984): 151-71.

Anderson, Benedict. Imagined Communities. Reflections on the Origin and Spread of Nationalism. 1983. London, New York: Verso, 1990.

Berg, Mary C. "Writing for Her Life. The Essays of Clorinda Matto de Turner". Reinterpreting the Spanish American Essay. Women Writers of the $19^{\text {th }}$ and $20^{\text {th }}$ Centuries. Doris Meyer, ed. Austin: University of Texas Press, 1995. 10-26.

Bhabha, Homi. "Introduction: Narrating the Nation". Nation and Narration. Homi K. Bhabha, ed. London: Routledge, 1990. 2-7

Bennington, Geoffrey. "Postal Politics and the Institution of the Nation". Nation and Narration. Homi K. Bhabha, ed. London: Routledge, 1990. 121-37

Cruz, Sor Juana Inés de la. Lírica. Barcelona: Bruguera, 1983.

Diccionario de la lengua española. Real Academia Española. Madrid: Espasa-Calpe, 1970.

García Pabón, Leonardo. "Máscaras, cartas y escritura femenina. Sobre la obra de Adela Zamudio (1854-1928)". Romance Languages Annual 5 (1993): 401-07.

Gómez de Avellaneda, Gertrudis. "La mujer". Obras Literarias. Tomo V. Madrid, 1871. 285-306. 
González Echevarría, Roberto. "The Case of the Speaking Statue: Ariel and the Magisterial Rhetoric of the Latin American Essay". The Voice of the Masters. Writing and Authority in Modern Latin American Literature. 1985. Austin: University of Texas Press, 1988.

Gorriti, Juana Manuela. Misceláneas. Colección de leyendas, juicios, pensamientos, discursos, impresiones de viaje y descripciones americanas. Buenos Aires, 1878. La cocina ecléctica. Buenos Aires: Librería Sarmiento, 1977.

Hooks, Bell. Yearning, Race, Gender and Cultural Politics. Boston: South End Press, 1990.

Masiello, Francine. Between Civilization and Barbarism. Women, Nation, and Literary Culture in Modern Argentina. Lincoln, Nebraska: University of Nebraska Press, 1992.

Matto de Turner, Clorinda. Tradiciones cuzqueñas. Leyendas, biografias y hojas sueltas. Cuzco: n.p., 1954.

Boreales, miniaturas y porcelanas. Buenos Aires: Imprenta Juan A. Alsina, 1902.

Meyer, Doris. "Introduction. The Spanish American Essay. A Female Perspective". Reinterpreting the Spanish American Essay. Women Writers of the $19^{\text {th }}$ and $20^{\text {th }}$ Centuries. Doris Meyer, ed. Austin: University of Texas Press, 1995. 1-9

Montoya de Zayas, Ondina. "La Avellaneda en su tiempo". Homenaje a Gertrudis Gómez de Avellaneda. Memorias del Simposio en el centenario de su muerte. Gladys Zaldívar y Rosa Martínez Cabrera, eds. Miami: Universal, 1973. 111-31.

Parker, Andrew, Mary Russo, Doris Sommer y Patricia Yaeger. "Introduction”. Nationalisms and Sexualities. London, New York: Routledge, 1992. 1-18

Santos, Nelly. "Las ideas feministas de Gertrudis Gómez de Avellaneda". Homenaje a Gertrudis Gómez de Avellaneda. Memorias del Simposio en el centenario de su muerte. Gladys Zaldívar y Rosa Martínez Cabrera, eds. Miami: Universal, 1973. $132-41$

Pratt, Mary Louise. "Don't Interrupt me. The Gender Essay as Conversation and Countercanon". Reinterpreting the Spanish American Essay. Women Writers of the $19^{\text {th }}$ and $20^{\text {th }}$ Centuries. Doris Meyer, ed. Austin: University of Texas Press, 1995. 10-26

Zamudio, Adela. Poetisa, educadora, polemista. Cochabamba, Bolivia: Canelas S.A., 1977. 